\title{
Effect of interleukin 12 (IL-12) on embryonic development and yolk sac vascularisation
}

\author{
Nisari $\mathrm{M}^{1}$, Ulger $\mathrm{H}^{1}$, Unur $\mathrm{E}^{1}$, Karaca $\mathrm{O}^{2}$, Ertekin $\mathrm{T}^{1}$ \\ Department of Anatomy, Erciyes University Faculty of Medicine, Kayseri, Turkey. mehtapnisari@gmail.com
}

\begin{abstract}
Background: In the recent days there has been an increase in diseases known as "angiogenic diseases" characterized by pathologic vascularisation. In the rat, the development of embryonic vessel starts to occur at 9.5 days of gestation. In mammals, the vascular system starts developing in a very early embryonic stage. The majority of rat embryo circulation system gets complete approximately at $11-12$ days. Therefore the in vitro study of 9.5 - 11.5-day old embryo culture could be a suitable model to study the effects of angiogenic and antiangiogenic substances on yolk sac vascularisation. In the present study, the effects of Interleukin-12 (IL-12) on the yolk sac vascularisation are investigated during the in vitro embryo culture, where the latter angiogenic factor was added to serum.

Methods: After 48-hour culture period, effects of different doses of IL-12 (50 ng/ml, $100 \mathrm{ng} / \mathrm{ml}$, and $200 \mathrm{ng} / \mathrm{ml})$ were estimated morphologically.

Results: According to morphologic scoring system, the total morphologic score, yolk sac diameter, crown rump length, and somite number were retarded in all experimental groups when compared to control. These developmental retardations were statically significant. There was also a poor development in the yolk sac vascularisation and the heart. Conclusion: As a result, the IL-12 could cause developmental retardation of embryos owing to its antiangiogenic effect (Tab. 3, Fig. 2, Ref. 39). Text in PDF www.elis.sk.

Key words: interleukin 12, vascularisation, yolk sac, embryo culture.
\end{abstract}

The cardiovascular system is the earliest system to begin its development in order to take over the functional role in providing the metabolic requirements for a rapidly growing embryo (1). In rats, the primordia of blood vessels appear around the day 9.5 of gestation, i.e. when the mesodermal germ layer is formed. Blood islands develop in the wall of the yolk sac as somites begin to form but there is no vascular connection with the vessels developing in situ in the body of the embryo. After blood islands are formed, they fuse and give rise to a primary vascular plexus $(2,3)$. Then by day 11-12 of gestation, the circulatory system is established. At this time the nutritional and informational molecules are transported via the vessels from the yolk sac to the embryo (4).

The formation of new blood vessel is a complex and controlled process in normal embryonic development, female reproductive cycle and wound healing (2).

Vasculogenesis and angiogenesis are the major forms of blood vessel formation. Vasculogenesis is the formation of blood vessels in situ from angioblast whereas angiogenesis is the process where new vessels grow from pre-existing blood vessels (5).

Angiogenesis depends on the balance between angiogenic and antiangiogenic factors. Previous studies reported that Inter-

${ }^{1}$ Department of Anatomy, Erciyes University Faculty of Medicine, Kayseri, Turkey, and ${ }^{2}$ Department of Anatomy, Balikesir University Faculty of Medicine, Balikesir, Turkey

Address of correspondence: M. Nisari, Department of Anatomy, Erciyes Medical University, Talas Street, 38039, Kayseri, Turkey

Phone: +90.352.2076666, Fax: +90.352.4375285 leukin-12 (IL-12) has an antiangiogenic effect on vessel development (6-8).

IL-12 is a glycoprotein heterodimer of $75 \mathrm{kD}$ and a strong pro-inflammatory cytokine (9). IL-12 is composed of $\alpha$-chain (p35 subunit) and a $\beta$-chain ( $\mathrm{p} 40$ subunit) linked by disulphide bridge to form the biologically active $74 \mathrm{kDa}$ heterodimer. It is produced by phagocytic cells, B cells and dendritic cells (10). IL-12 is recognized as a master regulator of adaptive type 1, cell-mediated immunity, the critical pathway involved in protection against neoplasia and many viruses. This is supported by the analysis of numerous animal $(11,12)$ and human clinical studies that can be attributed to improved clinical outcome (13) and mechanisms of IL-12-based therapy (14) to strong type 1 responses in situ. Since the initial preclinical and clinical studies of IL-12, done over a decade ago, the basic and translational science studies have contributed to the greater understanding of IL-12 immunobiology. In addition to its noted effects in the priming of Thelper 1 (TH1) cell responses and interferon-gamma (IFN- $\gamma$ ) production by T and natural killer (NK) cells, more recent studies support its critical role as a third signal for CD8+ T cell differentiation $(15,16)$, and its ability to serve as an important factor in the reactivation and survival of memory CD4+ T cells (17). This is particularly relevant in the repolarisation of CD4+ T cells from dysfunctional antitumour $\mathrm{T}$ helper 2 (TH2) into TH1 cells in the cancer setting (18).

The in vitro culture of post-implantation rat embryos from 9.5 to 11.5 days is possible in homologous serum using the method described by New (19), such that the development of embryos in 
vitro is comparable to that in vivo (20). Brunda et al (6), as well as Tahara et al (21) and Nastala et al (22) showed that IL-12 has a potent in vivo antitumor and antimetastatic activity against murine tumors. In addition, an important pro-inflammatory cytokine, IL-12 has been shown to have a potent immunomodulatory, antitumour, and anti-infection activity in vitro and in vivo (23). Several studies $(1,24-26)$ have been carried out to explain the effects of vascular endothelial growth factor (VEGF), anti-fibroblast growth factor-2 (anti-FGF-2 or anti-bFGF), fibroblast growth factor-9 (FGF-9) and angiostatin (K1-3) by using embryo culture technique in rats. But there are no data about IL-12's embryotoxicity or teratogenicity. The aim of the present study was to investigate the in vitro effects of interleukin-12 on embryonic development during the period of organogenesis in the rat.

\section{Methods}

\section{Timing of mating and pregnancy}

All protocols were approved by the Animal Care and Use Committee (Ethics Committee) of Erciyes University. Wistar rats were obtained from the Clinical and Experimental Research Centre, Medical Faculty of Erciyes University. The female rats (approximately at 8 weeks of age and weighing (175-200 g) were paired with their male partners in cages at about 5:00 pm and left overnight. The females were checked for the presence of vaginal plugs as an indication of mating and hence fertilisation. On the assumption that mating occurred around midnight, the female was considered to be 0.5 -day pregnant at noon the following day.

\section{Culture of the whole embryo}

At 9.5 days of gestation, the embryos (approximately 10 embryos from each pregnant rat) were removed from the mother by explantation procedure described by New (19). The pregnant rat was anaesthetised with diethyl ether. When complete anaesthesia was achieved, as assessed by the lack of blink reflex, the animals were placed in a supine position with a nose cone containing ether-soaked pads placed over the nose to ensure continual anaesthesia. The abdomen was cleaned with $70 \%$ ethanol and opened by midline incision in the anterior wall, and the viscera with their mesenteries were cleared to expose the bifurcation of the abdominal aorta into the common iliac arteries. A volume of 8-10 $\mathrm{ml}$ of blood was withdrawn from the aorta with a $10-\mathrm{ml}$ syringe and immediately centrifuged at 3,000 revolutions per minute for five minutes to obtain serum which was used as culture medium. The uterine horns containing the conceptuses were excised and placed in Hank's balanced salt solution (HBSS) (Sigma) at $37^{\circ} \mathrm{C}$.

After this stage, the procedure was carried out in a laminar flow cabinet. The uterus was cut into individual conceptuses, and by using jeweller's forceps, the uterine tissue was separated from the roundish decidua by making an incision along its superior border. Through the incision, the decidua were gently removed and placed into fresh HBSS at $37^{\circ} \mathrm{C}$. Under a dissecting microscope, the decidual tissue around the conceptus was dissected and one half removed so that the conceptus was left in the other half. The conceptus was gently and carefully dislodged into HBSS. While taking care not to damage the closely apposed visceral yolk sac, the parietal yolk sac and Reichert's membrane were removed by grasping them with two pairs of forceps at the embryonic pole of the egg cylinder and ripping the membrane along its length, finally removing it completely at the base of the ectoplacental cone.

\section{Occurring the experimental groups}

In order to assess the effect of IL-12 (Sigma-Aldrich, USA) on total embryonic growth, embryos were divided into a total of four groups (10 embryos per one group) of which one was a control and three were experimental. The control group of embryos was cultured in whole rat serum (WRS). The administration dosages of IL-12 were determined according to the data gained from previous studies $(10,27)$. Experimental groups were cultured 50, 100 and $200 \mathrm{ng} / \mathrm{ml}$ IL-12 per embryo. The embryos were cultured according to the method described by New (19). After 48-hour culture, the embryos from each group were examined under a dissecting microscope and assessed according to the morphological scoring system which takes account of the growth and differentiation of different embryological features, including the appearance of yolk sac circulation, allantois, body flexion, heart, caudal neural tube, hindbrain, midbrain, forebrain, otic system, optic system, olfactory system, branchial arches (bars), maxillary processes, mandibular processes, forelimbs, hindlimbs and somite number (28).

The data of morphological score and somite number, yolk sac diameter and crown-rump length were statistically analysed. All datasets were subjected to normality test using the KolmogorovSmirnov method and the data were reported as either mean \pm standard deviation $(\mathrm{x} \pm \mathrm{SD})$ (for normally distributed data) or as median with $25-75 \%$ percentile (for skewed data). Comparison between the groups was made using the One Way Analysis of Variance (ANOVA; multiple comparisons were carried out with Tukey Test) or the Kruskal-Wallis Test (KW; Post-Hoc comparisons were carried out with Tukey Test). Statistical significance was set at $\mathrm{P}<0.001$. All analyses were performed with the statistical package for scientist (SIGMASTAT) Windows version 3.10.

\section{Results}

The embryos cultured in IL-12 showed severe growth retardation in all embryonic primordia when compared to embryos grown only in WRS (Figs 1 and 2). IL-12 affected the embryos in a dose-dependent manner and higher doses of IL-12 increased the retardations of embryonic growth and development according to morphological scoring system (Tabs 1 and 2). The lower morphological scores were accompanied by poor yolk sac vessel development according to the scoring system, some failure of fusion of the neural folds, incomplete embryonic flexion, and retarded development of otic, optic and olfactory systems, branchial bars, maxillary and mandibular processes and limbs. In addition to total morphological scores, the yolk sac diameter, somite numbers and the crown-rump length of 11.5-day embryos grown in IL-12 was significantly decreased compared to normal embryonic development on day 11.5 in WRS. Statistical studies showed that there was a significant decrease $(\mathrm{p}<0.001)$ in total morphological score, 


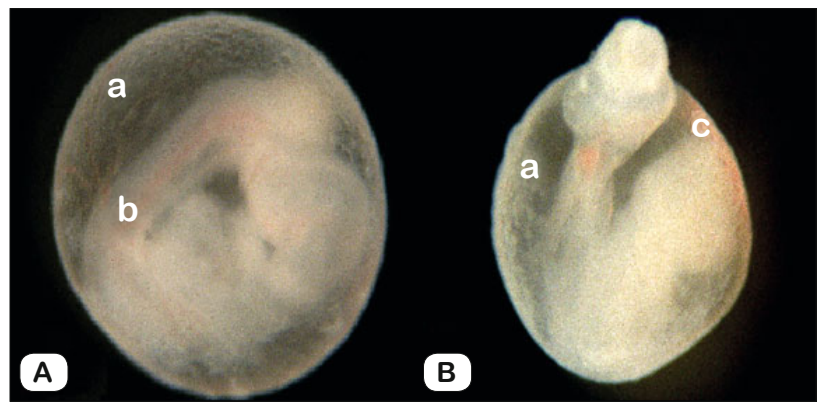

Fig. 1. Rat embryos enclosed in the yolk sac at $\mathbf{1 1 . 5}$ days of gestation following 48-h culture period in WRS (A) and in WRS+200 ng/ml IL12 (B) a - yolk sac vessel; b - yolc sac vessel, $\mathrm{c}$ - blood islands.

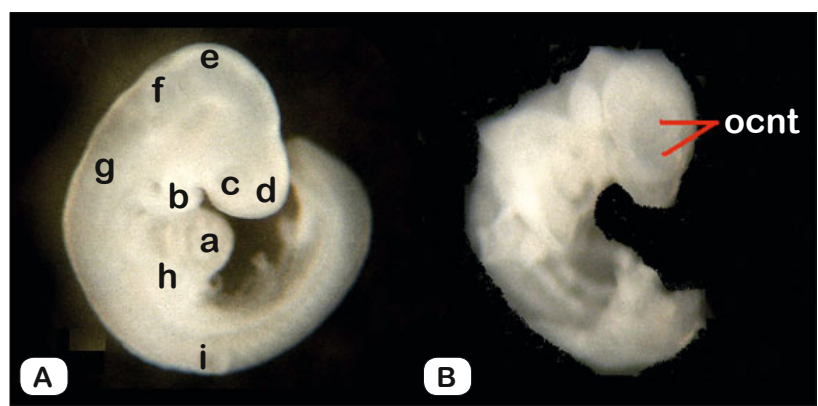

Fig. 2. Rat embryos outside the yolk sac at 11.5 days of gestation following 48-h culture period in WRS (A) and in WRS $+200 \mathrm{ng} / \mathrm{ml} \mathrm{IL-}$ 12 (B) a - heart, $b$ - branchial bar, $c$ - optic vesicle, $d$ - forebrain, $e$ - midbrain, $f$ - hindbrain, $g$-otic vesicle, $h$ - fore limb, $\mathbf{i}$ - somites, ocnt - open cranial neural tube.

yolk sac diameter, crown-rump length, and somite number. Mean morphological scores for the embryos grown in WRS in the presence of 50, 100 and $200 \mathrm{ng} / \mathrm{ml}$ IL-12 were $58.45 \pm 0.47,53.20 \pm$ $1.23,50.90 \pm 1.53$ and $41.30 \pm 2.93$, respectively. Yolk sac diameter was $3.17 \pm 0.14 \mathrm{~mm}$ in control group and $2.86 \pm 0.14,2.60$ \pm 0.12 and $2.31 \pm 0.13 \mathrm{~mm}$ in experimental groups, respectively.

While in the control group, the mean crown-rump length was $3.17 \pm 0.14 \mathrm{~mm}$, in experimental groups it diminished gradually due to the dose of IL-12 $(2.86 \pm 0.14,2.60 \pm 0.12$ and $2.31 \pm 0.13$ $\mathrm{mm})$. Median value of the somite numbers was 24 (24-25) in control group and it was diminished to 23 (21-23), 21 (20-21) and 17 (16-17), respectively in experimental groups. While the yolk sac of embryos grown in WRS had a fully developed yolk sac plexus of vessels, the yolk sac of embryos grown in WRS + $100 \mathrm{ng} / \mathrm{ml} \mathrm{IL-12}$ was just establishing the vitelline circulation and had few yolk sac vessels, and the WRS $+200 \mathrm{ng} / \mathrm{ml} \mathrm{IL-12}$ groups had no vessels and still had only blood islands (Figs $1 \mathrm{~A}$ and B). Developmental retardations in the neural tube formation were also found in all experimental groups when compared to control group. There was an open neural tube in both cranial and caudal regions in the embryos that had been grown in the presence of IL-12 (Figs 2A and B). While the three-chambered heart of embryos grown in rat serum was normal ( 2 atrial, 1 ventricular), the heart development in embryos grown in the presence of IL-12 had not reached this level (Tab. 3).

The morphological analysis showed that all embryos grown in WRS+IL-12 had open caudal neural tubes and less of neural system developed. In conclusion, IL-12 caused growth retardation in all experimental groups.

\section{Discussion}

Since the longevity of people suffering from cancer is increasing a lot of studies are striving to improve their quality of life. Early detection of cancer as a result of finding better methods of assessment is in progress. On the other hand, methods used for cancer treatment (such as chemotherapy, radioterapy) have many side effects. Recently some studies emerged focused to reduce these side effects. The purpose of this research is to eliminate only cancer cells without harming the normal cells. In recent years, similar studies have been widely acknowledged. Recent studies have shown that some experimental antiangiogenic drugs are reliable in cancer treatment. In addition, the drugs used in these studies show that they prevent vascularisation and then eliminate the cancer cells. However, today the commonly used treatments have fewer side effects (29-30).

There are many antiangiogenic drugs preventing the first new blood vessel formation. Endothelial cells grow in the inner layer of blood vessels. These new blood vessels cannot occur without endothelial cells. Some antiangiogenic drugs made in laboratory are proteins in structure and are the same proteins as those in the organism. These proteins reduce the growth of endothelial cells. They include e.g. Endostatin (31), Angiostatin (32) and Thrombospondin 1 (33) ve IL-12 (10)'dir.

Embryonic and adult growth processes are a pre-requisite for the formation of a functional vascular system, which is essential for proper development of vertebrate embryos, as well as for growth, regeneration and survival of adults (26). The formation

Tab. 1. Statistical analyses of in vitro embryonic development in whole rat serum (WRS), and interleukin-12 (IL-12).

\begin{tabular}{|c|c|c|c|c|c|c|}
\hline$\underline{\text { Parameters }}$ & & Control & $50 \mathrm{ng} / \mathrm{ml} \mathrm{IL-12}$ & $100 \mathrm{ng} / \mathrm{ml} \mathrm{IL-12}$ & $200 \mathrm{ng} / \mathrm{ml} \mathrm{IL-12}$ & $\mathrm{P}$ \\
\hline $\begin{array}{l}\text { Total morfological } \\
\text { score }\end{array}$ & $\mathrm{X} \pm \mathrm{SD}$ & $58.45 \pm 0.47$ & $53.20 \pm 1.23$ & $50.90 \pm 1.53 *$ & $41.30 \pm 2.93 * * *$ & $<0.001 \S$ \\
\hline $\begin{array}{l}\text { Yolk sac } \\
\text { diamater }\end{array}$ & $\mathrm{X} \pm \mathrm{SD}$ & $3.17 \pm 0.14$ & $2.86 \pm 0.14$ & $2.60 \pm 0.12 *$ & $2.31 \pm 0.13 * * *$ & $<0.001 \S$ \\
\hline $\begin{array}{l}\text { Crown-rump } \\
\text { lenght }\end{array}$ & $\mathrm{X} \pm \mathrm{SD}$ & $2.80 \pm 0.11$ & $2.46 \pm 0.17$ & $2.12 \pm 0.13^{*}$ & $1.99 \pm 0.14 * *$ & $<0.001 \S$ \\
\hline Somite Number & $\begin{array}{c}\text { Median } \\
(25 \%-75 \%)\end{array}$ & $\begin{array}{c}24.20 \pm 0.68 \\
(24-25)\end{array}$ & $\begin{array}{c}23.00 \pm 1.45 \\
(21-23)\end{array}$ & $\begin{array}{c}21.80 \pm 1.21 \\
(20-21)\end{array}$ & $\begin{array}{c}17.80 \pm 1.06^{* *} \\
(16-17)\end{array}$ & $<0.001 \dagger$ \\
\hline
\end{tabular}

$\S$ One Way Analysis of Variance is applied

$\dagger$ Kruskal-Wallis test is applied 
Tab. 2. The development of yolk sac circulation in whole rat serum (WRS), and interleukin-12 (IL-12).

\begin{tabular}{|c|c|c|c|c|c|c|}
\hline The score of yolk sac circulation & & $\begin{array}{l}\text { The number } \\
\text { of embryo }\end{array}$ & Control & $50 \mathrm{ng} / \mathrm{ml} \mathrm{IL}-12$ & $100 \mathrm{ng} / \mathrm{ml} \mathrm{IL}-12$ & 200 ng/ml IL-12 \\
\hline No visible or scattered blod islands & 0 & 10 & - & - & - & - \\
\hline Corona of blood island $\mathrm{w}$ or w/o anastomoses & 1 & 10 & - & - & - & 6 \\
\hline Vitelline vessel with few yolk sac vessel & 2 & 10 & - & 3 & 4 & - \\
\hline Full yolk sac plexus of vessel & 3 & 10 & - & 1 & - & 2 \\
\hline Origins of two vitelline vessels migrated closer to each other & 4 & 10 & 10 & 6 & 6 & 2 \\
\hline
\end{tabular}

Tab. 3. The development of heart in whole rat serum (WRS), and interleukin-12 (IL-12).

\begin{tabular}{|c|c|c|c|c|c|c|}
\hline The score of heart & & $\begin{array}{l}\text { The number } \\
\text { of embryo }\end{array}$ & Control & $50 \mathrm{ng} / \mathrm{ml} \mathrm{IL-12}$ & 100 ng/ml IL-12 & $200 \mathrm{ng} / \mathrm{ml} \mathrm{IL-12}$ \\
\hline Beating $\mathrm{S}$ shaped cardiac tube & 2 & 10 & - & - & - & 2 \\
\hline Bulbus cordis, atrium commune and ventriculus communis & 3 & 10 & - & 2 & 8 & 7 \\
\hline Three chambered appearance & 4 & 10 & 10 & 8 & 2 & 1 \\
\hline Four chambered appearance & 5 & 10 & - & - & - & - \\
\hline
\end{tabular}

of vascular system is one of the earliest and most important events during organogenesis in the developing embryo because the growing organism needs a transportation system to supply oxygen and nutrients and to remove waste products. Two distinct processes termed vasculogenesis and angiogenesis lead to the development of a complex vasculature covering the entire body (34). Angiogenesis refers to the process of new blood vessel formation from a pre-existing vasculature which occurs either under physiological or pathological conditions (35). Vasculogenesis is a de novo process by which the progenitor stem cells differentiate and give rise to a replacement vascular network (36).

Brunda et al (6), as well as Tahara et al (21) and Nastala et al (22) showed that IL-12 has a potent in vivo antitumour and antimetastatic activity against murine tumours. Interestingly, the efficacy of IL-12 in immune-incompetent mice was greatly reduced, but not abolished. By building on these observations, in 1995, Folkman and colleagues discovered the potent antiangiogenic properties of IL-12. They found that IL-12 treatment inhibited basic fibroblast growth factor-induced corneal neovascularization in both immunocompetent and immunodeficient mice. Suppression of angiogenesis by IL-12 was dependent on its ability to induce IFN- $\gamma$ expression. Accordingly, administration of IFN- $\gamma$ reproduced the antiangiogenic effects promoted by IL-12 (37).

IL-12 treatment was shown to almost completely inhibit corneal neo-vascularisation in mice (10). This potent suppression of angiogenesis was prevented by the administration of IFN- $\gamma$ neutralizing antibodies, suggesting that the suppression was mediated through IFN- $\gamma$. In addition, the administration of IFN- $\gamma$ reproduced the anti-angiogenic effects observed during treatment with IL-12 (37). Thus, IL-12 strongly inhibits neo-vascularization and this effect is not mediated by a specific cell type of the immune system. Instead, IL-12 induces IFN- $\gamma$ that appears to play a critical role as a mediator of the anti-angiogenic effects of IL-12 (38).

In a different experimental model, researchers showed that the systemic administration of IL-12 and intermittent doses of IL-2 induced a complete regression of metastatic murine renal carcinoma, preceded by recruitment of CD8+ T cells, vascular injury, disrupted tumour neo-vascularisation, and apoptosis of both endothelial and tumour cells. The IL-12/IL-2 combination synergistically enhanced cell surface FasL expression on CD8+ T lymphocytes in vitro and induced Fas and FasL expression within tumours via IFN- $\gamma$-dependent mechanism in vivo. This therapy also inhibited tumour neo-vascularisation and induced rapid destruction of tumour-associated endothelial cells and tumour regression by mechanisms that depended critically on endogenous IFN- $\gamma$ production and intact Fas/FasL pathway (10).

Indeed, some recent studies have shown that IL-12 may mediate anti-tumour and anti-angiogenic effects dependent on induction of IFN- $\gamma$ and CXCR3 ligands but requiring neither NK nor T cells. IL-12 was demonstrated to be able to induce an anti-angiogenesis effect of IL-12 on human as well as on murine tumours in NKdepleted SCID mice using fibroblasts genetically engineered to secrete this cytokine. The neo-vascularisation surrounding the tumour was remarkably inhibited in the area in which the IL12-secreting fibroblasts were implanted, resulting in the suppression of tumour growth. Lectin staining in tumour sample sections also showed a significant reduction in the number of vessels. The RNA expression of IFN- $\gamma$ and IP-10 was stimulated in endothelial cells cultured with IL-12. It was also found that IL-12 downregulated the expression of the endothelial cell mitogens vascular endothelial growth factor and basic fibroblast growth factor (27).

The effect of IL-12 was investigated in vitro on embryonic yolk sac vascularisation. In this research, depending on the dose, it was found to inhibit the development of yolk sac and heart vascularisation. In addition, the total development of embryos grown in the culture media with IL-12 declined greatly.

In the present study, in vitro effects of IL-12 were tested on embryo culture. The results showed that total embryonic growth was normal in WRS as opposed to the experimental groups in which IL-12 was added to WRS and decreased depending on the dose of IL-12. Embryonic retardations were seen in total embryonic growth especially yolk sac diameter and vascularisation, crown-rump length, somite number, body flexion and neural tube development. When post-implantation embryos were cultured in the presence of certain antiangiogenic molecules, similar regression was seen in embryonic growth, e.g with anti-bFGF (24) and 
angiostatin (26). Our results indicated that the addition of higher concentrations of IL-12 resulted in growth retardation and some malformations. Those findings may be caused by the reduction in yolk sac functions, because the yolk sac decreased in size and vascularisation in the presence of these higher concentrations. It is well known that the yolk sac is an especially important placental organ in rodents at this time of embryonic development. It has been shown to be the primary source of exchange between the embryo and mother during early embryogenesis before the chorioallantoic placenta becomes functional (19). Together with a wide range of other in vitro studies dealing with the teratogenicity of several different molecules, the present findings suggest that the rat postimplantation embryo culture system is a very useful method for teratological studies and also particularly suitable for the assessment of specific effects on morphogenetic events occurring during early organogenesis in mammalian embryos.

\section{References}

1. Ulger H, Ozdamar S, Unur E, Pratten MK. The Effect of Vascular Endothelial Growth Factor on in vitro Embryonic Heart Development in Rats. Anat Histol Embryol 2004; 33: 334-338.

2. Wagner RC. Endothelial cell embryology and growth. Advences in micro circulation 1980; 9: 45-75.

3. Risau W. Embryonic angiogenesis factors. Pharmacol Ther 1991; 51 (3): $371-376$

4. Ulger H. The Growth Promoting Effects Of bFGF, VEGF and PDECGF On Embryonic Development and Yolk Sac Vascularisation, PhD Thesis, Department of Human Anatomy and Cell Biology University of Nottingham, England 1997.

5. Yan Li, Xiao-yu Wang, Ting Wu, Manli Chuai, Kenneth Ka Ho Lee, Li-jing Wang, Xuesong Yang. PTEN is involved in modulation of vasculogenesis in early chick embryos. Biol Open 2013; 2 (6): 587-595.

6. Brunda MJ, Luistro L, Warrier RR, Wright RB, Hubbard BR, Murphy M, Wolf SF, Gately MK. Antitumor and antimetastatic activity of interleukin 12 against murine tumors. J Exp Med 1993; 178 (4): 1223-1230.

7. Fujiwara H, Hamaoka T. Antitumor and antimetastatic effects of interleukin 12. Cancer Chemother Pharmacol 1996; 38 Suppl: S22-26.

8. Wigginton JM, Gruys E, Geiselhart L, Subleski J, Komschlies KL, Park JW, Wiltrout TA, Nagashima K, Back TC, Wiltrout RH. IFNgamma and Fas/FasL are required for the antitumor and antiangiogenic effects of IL-12/pulse IL-2 therapy. J Clin Invest 2001; 108 (1): 51-62.

9. Antunica AG, Karaman K, Znaor L, Sapunar A, Buško V, Puzović V. IL-12 concentrations in the aqueous humor and serum of diabetic retinopathy patients Graefes Arch Clin Exp Ophthalmol 2012; 250 (6): 815-821.

10. Colombo MP, Trinchieri G. Interleukin-12 in antitumor immunity and immunotherapy. CytokineGrowth FactorRev 2002; 13: 155-168.

11. Hung K, Hayashi R, Lafond-Walker A, Lowenstein C, Pardoll D, Levitsky H. The central role of CD4(+) T cells in the antitumor immune response. J Exp Med 1998; 188 (12): 2357-2368.

12. Tatsumi T, Huang J, Gooding WE, Gambotto A, Robbins PD, Vujanovic NL, Alber SM, Watkins SC, Okada H, Storkus WJ. Intratumoral delivery of dendritic cells engineered to secrete both interleukin (IL)-12 and IL-18 effectively treats local and distant disease in association with broadly reactive Tc1-type immunity. Cancer Res 2003; 63 (19): 6378-6386.
13. Galon J, Costes A, Sanchez-Cabo F, Kirilovsky A, Mlecnik B, Lagorce-Pagès $\mathrm{C}$, Tosolini $\mathrm{M}$, Camus $\mathrm{M}$, Berger $\mathrm{A}$, Wind $\mathrm{P}$, Zinzindohoué F, Bruneval P, Cugnenc PH, Trajanoski Z, Fridman WH, Pagès F. Type, density, and location of immune cells within human colorectal tumors predict clinical outcome. Science 2006; 313: (5795): 1960-1964.

14. van Herpen CM, Looman M, Zonneveld M, Scharenborg N, de Wilde PC, van de Locht L, Merkx MA, Adema GJ, de Mulder PH. Intratumoral administration of recombinant human interleukin 12 in head and neck squamous cell carcinoma patients elicits a T-helper 1 profile in the locoregional lymph nodes. Clin Cancer Res 2004; 10 (8): 2626-2635.

15. Curtsinger JM, Lins DC, Mescher MF. Signal 3 determines tolerance versus full activation of naive CD8 T cells: dissociating proliferation and development of effector function. J Exp Med 2003; 197 (9): 1141-1151.

16. Kalinski P, Hilkens CM, Wierenga EA, Kapsenberg ML. T-cell priming by type- 1 and type- 2 polarized dendritic cells: the concept of a third signal. Immunol Today 1999; 20 (12): 561-567.

17. Yoo JK, Cho JH, Lee SW, Sung YC. IL-12 provides proliferation and survival signals to murine $\mathrm{CD} 4+\mathrm{T}$ cells through phosphatidylinositol 3-kinase/Akt signaling pathway. J Immunol 2002; 169 (7): 3637-3643.

18. Wesa A, Kalinski P, Kirkwood JM, Tatsumi T, Storkus WJ. Polarized type-1 dendritic cells (DC1) producing high levels of IL-12 family members rescue patient Th1-type anti-melanoma CD4+ $\mathrm{T}$ cell responses in vitro. J Immunother 2007; 30 (1): 75-82.

19. New DA. Whole embryo culture and the study of mammalian embryos during organogenesis. Biol Rev Camb Philos Soc 1978; 53 (1): 81-122.

20. New DA, Coppola PT, Cockroft DL. Comparison of growth in vitro and in vivo of post-implantation rat embryos. J Embryol Exp Morphol 1976: 36 (1): 133-144.

21. Tahara H, Zeh HJ 3rd, Storkus WJ, Pappo I, Watkins SC, Gubler U, Wolf SF, Robbins PD, Lotze MT. Fibroblasts genetically engineered to secrete interleukin-12 can suppress tumor growth in vivo and induce antitumor immunity to a murine melanoma. Cancer Res 1994; 54 (1): 182-189.

22. Nastala CL, Edington HD, McKinney TG, Tahara H, Nalesnik MA, Brunda MJ, Gately MK, Wolf SF, Schreiber RD, Storkus WJ et al. Recombinant IL-12 administration induces tumor regression in association with IFN- $\gamma$ production. J Immunol 1994; 153 (4): 1697-1706.

23. Wang Y, Fan KT, Li JM, Waller EK. The regulation and activity of interleukin-12.

24. SourceDepartment of Hematology and Medical Oncology, Winship Cancer Institute, Emory University, Atlanta, GA Front Biosci (Schol Ed) 2012; 4: 888-899.

25. Unur E, Ulger H, Ekinci N, Hacialiogullari M, Ertekin T, Kilic E. Effect of Anti-Basic Fibroblast Growth Factor (Anti-bFGF) on In Vitro Embryonic Development in Rat. Anat Histol Embryol 2009; 38: 241-245.

26. Tekinarslan İ, Unur E, Ülger H, Ekinci N, Ertekin T, Hacialiogullari M, Arslan S. The Effects of FGF-9 on in vitro embryonic development. Balkan Med J 2011; 28: 18-22.

27. Ertekin T, Ulger H, Nisari M, Karaca O, Unur E, Sahin U, Elmali F. Effects of Angiostatin on in vitro Embryonic Rat Development. Kafkas Univ Vet Fak Derg 2011; 17 (5): 843-847.

28. Duda DG, Sunamura M, Lozonschi L, Kodama T, Egawa S, Matsumoto G, Shimamura H, Shibuya K, Takeda K, Matsuno S. Direct in vitro evidence and in vivo analysis of the antiangiogenesis effects of interleukin 12. Cancer Res 2000; 60 (4): 1111-1116. 
29. Van Maele-Fabry G, Delhaise F, Picard JJ. Morphogenesis and quantification of the development of post-implantation mouse embryos in vitro. Toxicol In Vitro 1990; 4 (2): 149-156.

30. Zhang ZL, Wang JH, Liu XY. Current strategies and future directions of antiangiogenic tumor therapy. 2003; 35 (10): 873-880.

31. Burke PA, DeNardo SJ. Antiangiogenic agents and their promising potential in combined therapy. Crit Rev Oncol Hematol 2001; 39 (1-2): $155-171$.

32. Kim YM, Hwang S, Kim YM, Pyun BJ, Kim TY, Lee ST, Gho YS, Kwon YG. Endostatin blocks vascular endothelial growth factor-mediated signaling via direct interaction with KDR/Flk-1. J Biolo Chem 2002; 277 (31): 27872-27879.

33. O'Reilly MS, Holmgren L, Shing Y, Chen C, Rosenthal RA, Moses M, Lane WS, Cao Y, Sage EH, Folkman J. Angiostatin: A novel angiogenesis inhibitör that mediates the supression of metastases by a lewis lung carcinoma. Cell 1994; 79 (2): 315-328.

34. Dawson DW, Pearce SF, Zhong R, Silverstein RL, Frazier WA, Bouck NP. CD36 mediates the in vitro inhibitory effects of thrombospondin-1 on endothelial cells. J Cell Biol 1997; 138 (3): 707-717.
35. Heinke J, Patterson C, Moser M. Life is a pattern: vascular assembly within the embryo. Front Biosci (Elite Ed) 2012; 4: 2269-2288.

36. Wang R, Gu Y, Zhang WD, Yan XN, Jin L, Wang XJ. Inhibition of tumor-induced angiogenesis and its mechanism by ardipusilloside I purified from Ardisia pusilla. J Asian Nat Prod Res 2012; 14 (1): 55-63.

37. Velazquez OC. Angiogenesis and Vasculogenesis: Inducing the growth of new blood vessels and wound healing by stimulation of Bone Marrow Derived Progenitor Cell Mobilization and Homing. J Vasc Surg 2007; 45 Suppl A: A39-47.

38. Voest EE, Kenyon BM, O'Reilly MS, Truitt G, D'Amato RJ, Folkman J. Inhibition of angiogenesis in vivo by interleukin 12. J Natl Cancer Inst 1995; 87 (8): 581-586.

39. Del Vecchio M, Bajetta E, Canova S, Lotze MT, Wesa A, Parmiani G, Anichini A. Interleukin-12: Biological Properties and Clinical Application Clin Cancer Res 2007; 13 (16): 4678.

Received August 16, 2013. Accepted September 18, 2013. 